\title{
Lessons from Capital Market History, Part 1
}

By Harry S. Marmer, CFA

[Editor's note: This article is the first of a two-part series arguing not only that investors should be interested in financial market history but that they can learn valuable lessons from it. The second article in the series will be published in the March 2017 issue. A complete version of the entire paper, including footnotes and a bibliography, is available online at www.cfapubs.org.]

A recent CFA Institute Magazine article asked the formidable question, "Should financial history matter to investors?" [September/October 2015 issue]. The author cited the results of a CFA Institute member survey, reporting that "when asked about the importance of economic and financial history to their success as investment professionals," an overwhelming majority (96\%) answered that it was either very or somewhat important.

However, the same article noted that "some may not know how to use this knowledge to make better investment decisions (or, at the very least, avoid poor ones)." The objective in this twopart series is to illustrate how the study of capital market history can provide investors with "helpful guidance on how historical perspectives can be incorporated into investment decision-making processes." To demonstrate the point, I examine popular beliefs and their inconsistency with several stylized facts of long-term capital market data. Along the way, I provide specific and important suggestions for analyzing financial data and present selected lessons and facts investors can employ in their long-termdecision-making process. Let's begin our journey through capital market history.

\section{UNPREDICTABLE BUSINESS AND STOCK MARKET CYCLES}

The popular financial press often features investment professionals predicting the direction of the business cycle or the stock market. This behavior leads investors to believe that business and stock market cycles repeat in a predictable manner. Typical educational sources imply this predictability using a classical smooth-waved chart to illustrate the business cycle. Even employing the word cycle to describe long-term business and stock market movements reinforces the idea that these "patterns" represent predictability and repeatability.

In examining long-term capital market data, it is often helpful to depict this quantitative information visually in order to better assess the evidence and determine if there are any particular patterns. In addition, visually inspecting the data is a good habit to develop in order to detect potential input errors.

Figure 1 shows 155 years of US business cycle history. Visually inspecting the long-term data gives one the impression that there is little predictability or cyclicality in the series. "This is perhaps an inevitable outcome given the changing nature of business cycles," wrote Serena $\mathrm{Ng}$ and Jonathan $\mathrm{H}$. Wright in their 2013 article "Facts and Challenges from the Great Recession for Forecasting and Macroeconomic Modeling." "The fact that business cycles are not all alike naturally means that variables that predict activity have a performance that is episodic."
Statistics for completed business cycles from 1854-2009 support this view. The "typical" US business cycle length over this time period averages 4.7 years (with a high degree of variability, as the standard deviation of the average cycle is 2.2 years). In other words, the underlying length of the business cycle has broadly ranged anywhere from 2.5 years to 6.9 years $68 \%$ of the time.

Stock market cycle statistics for the period between 1926 and 2016 support the fact that the length of a typical stock market cycle is highly variable, averaging 7 years with a standard deviation of 3.1 years (i.e., $68 \%$ of the time a stock market can range from 3.9 years to 10.1 years).

Since the length of business and stock market cycles is highly variable and not predictable, investors should avoid investment and policy decisions predicated on attempting to predict the length or the turning point of either business or stock market cycles. The historical data also suggests that money managers should be assessed over longer periods than the standard 3 or 4 years, as the average stock market cycle is 7 years.

Predicting the duration of the business cycle was aptly summarized by noted business-cycle analyst Victor

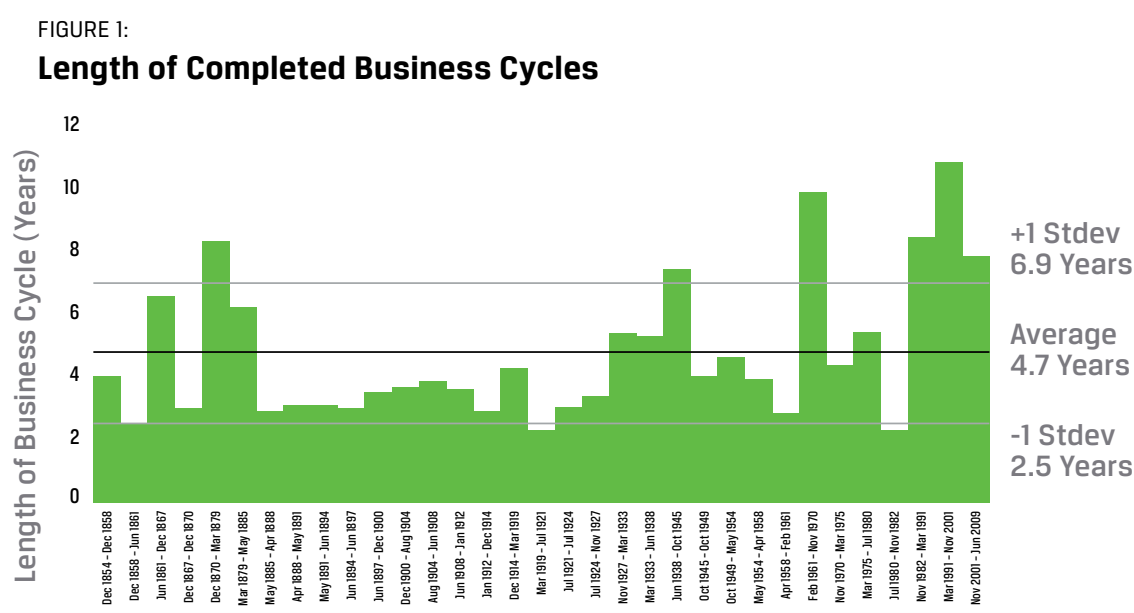

Sources: The National Bureau of Economic Research and Hillsdale Investment Management. Note: Business cycles above are based on trough-to-trough analysis. 
Zarnowitz, who said, "Few business cycle peaks are successfully predicted; indeed, most are publicly recognized only with lengthy delays."

\section{THE SHAPE OF STOCK RETURN DISTRIBUTIONS}

Investors employ market timing as a strategy if they believe they can "call the turns" in the market. Let us examine the challenges in implementing this strategy.

Figure 2 presents the distribution of monthly returns for the S\&P 500 Index over the past 89 years. This distribution appears non-normal, with long "fat" tails and a more peaked center in comparison to a normal return distribution. The kurtosis for this distribution is 9.7; a normal distribution has a kurtosis of 3 .

The abnormal shape of the distribution in Figure 2 represents, to some degree, the fact that stock returns are characterized by jumps. More specifically, financial prices tend to "jump, skip, and leap" up and down rather than change in a continuous fashion. As Svetlozar Rachev, Christian Menn, and Frank Fabozzi wrote in their book Fat-Tailed and Skewed Asset Return Distributions, "Heavy or fat tails can help explain larger price fluctuations for stocks over short time periods," resulting in a significant percentage of very good (and bad) returns occurring over a limited number of days.

Why do markets behave in this fashion? Noted mathematician and scientist Benoit Mandelbrot proposes that one possible source for these empirical

\section{FIGURE 2:}

\section{Distribution of Stock Market Returns}

S\&P 500 Monthly Return Relative Frequency, Jan. 1927-Mar. 2016

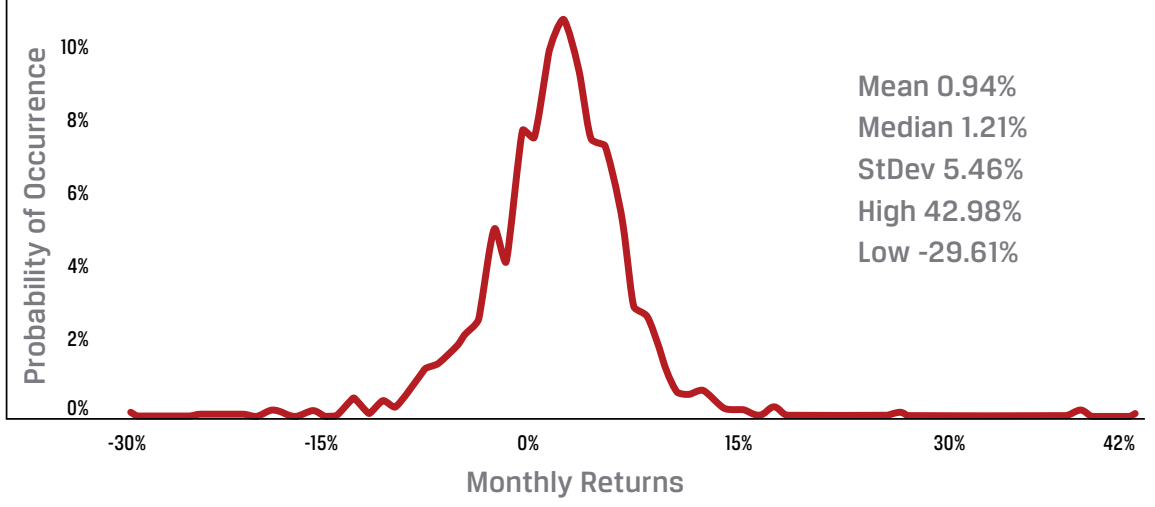

Source: Hillsdale Investment Management
FIGURE 3 :

Opportunity Costs of Missing Market Performance: $\$ 1,000$ Invested

S\&P 500 Index, Daily, 10 Years Ending 30 June 2016

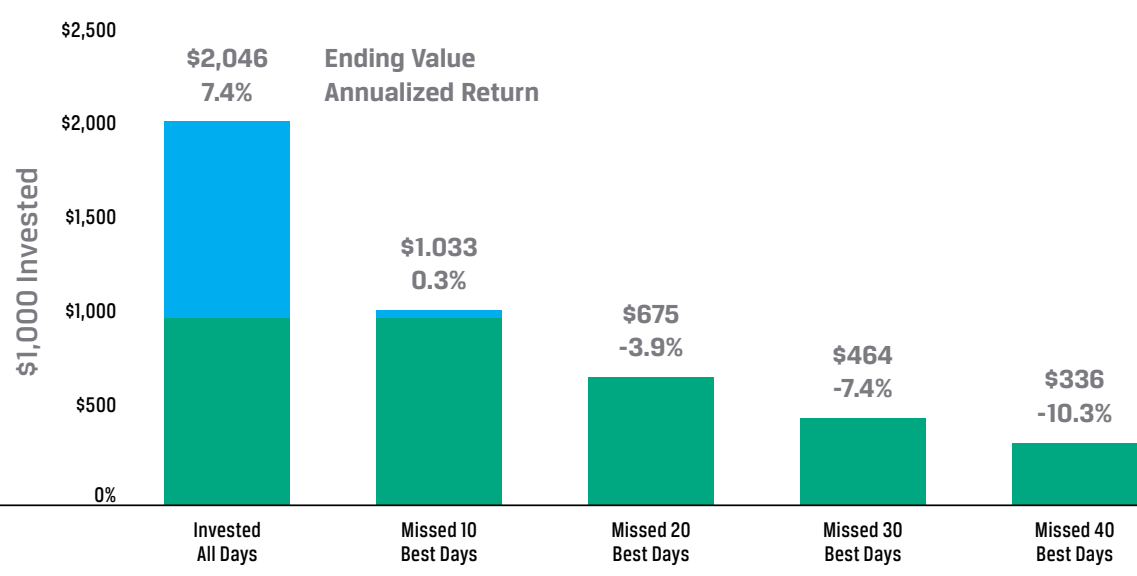

Source: Hillsdale Investment Management

traits is the world outside the markets, or "exogenous effects." Continuing with this theme, respected quant Paul Kaplan suggests that financial crises and bank failures, which have occurred throughout history, are to blame for fat-tailed return distributions. Others point at investor behaviorial biases as a primary driver of the heavy or fat tails in assetclass return distributions.

The non-normal distribution of stock returns helps explain why market timing has often been described as a "mug's game," or a low-odds strategy, as illustrated in Figure 3. (Theoretical studies support this hypothesis, finding that a sizeable success ratio of anywhere from $60 \%$ to $70 \%$ is required to beat a buy-and-hold strategy.)

In this example, $\$ 1,000$ invested in the market more than doubled over 10 years, but missing just the 10 best days resulted in virtually no growth of

capital. Of course, the flip side-missing the 10 worst days of market performance-presents the same challenge for investors. An intuitive rationale for the challenge in calling market turns is that the skill level required for market timing success is very high due to the lack of decision-making breadth of such a strategy. Nobel Prize-winning economist Paul Samuelson described the challenges in market timing best: "Scores of documented statistical studies attest that not one in ten 'timers' ends up getting back into the market at bargain prices lower than what they sold at earlier."

Given the empirical return distribution of markets, investors can increase the odds of successfully achieving their long-term policy mix not by market timing but by instead implementing a disciplined rebalancing policy back to the long-term policy asset mix. Analyzing the entire return distribution provides a finer appreciation for the challenges involved in succeeding in market timing. In conclusion, market timing is a low-odds strategy, as this approach runs counter to the very essence of how markets move over time.

Harry S. Marmer, CFA, is a partner at Hillsdale Investment Management and a member of CFA Society Toronto.

The author would like to thank the following people for their helpful comments: Kristin Spate, Michael Campbell, Paul Fahey, Peter Jarvis, Roger Clarke, and Stephen Beinhacker. All data presented is from Hillsdale's proprietary database unless indicated otherwise. 